\title{
Feasibility of Direct Seeding for Stand Establishment of Field-grown Basil
}

\author{
Brian A. Kahn ${ }^{1,3}$, Niels O. Maness ${ }^{1}$, Donna R. Chrz' \\ and Lynda K. Carrier ${ }^{2}$ \\ Department of Horticulture and Landscape Architecture, 358 Agricultural \\ Hall, Oklahoma State University, Stillwater, OK 74078-6027
}

Additional index words. Ocimum basilicum, herbs, transplanting

\begin{abstract}
Six experiments were conducted on 'Genovese' basil (Ocimum basilicum L.) in Oklahoma to study the feasibility of establishing basil in the field by direct seeding. Variables examined included use of raw seed or pelleted seed, seeding depth, seeding rate, and comparison with transplanting. Direct seeding was done using a hand-pushed planter (first four experiments), a tractor-drawn planter (fifth experiment), or both types of planter (sixth experiment). Plants were destructively harvested by machine. Stands were established successfully using transplants or using raw or pelleted seed with a handpushed planter. Planting at a depth of $\approx 10 \mathrm{~mm}$ resulted in lower yields than planting at a depth where seeds barely were covered with soil $(\approx 5 \mathrm{~mm})$. Seeding rates of $\approx 80 \mathrm{seeds} / \mathrm{m}$ led to higher final stands and higher yields than those obtained with seeding rates of $\approx 30$ seeds $/ \mathrm{m}$. These studies were not designed to test effects of plant population on basil yield, but data suggest that final stands above the common recommendation of one plant per $30.5 \mathrm{~cm}$ in rows spaced $90 \mathrm{~cm}$ apart may result in yield increases. Plots direct-seeded with the tractor-drawn planter failed to establish in the fifth experiment. Plants established using pelleted seed with the hand-pushed planter did not differ from plants established by transplanting in cumulative yields in the sixth experiment, even though the transplanting treatment allowed one additional harvest. The lowest cumulative yields in the sixth experiment came from plants established using pelleted seed with the tractor-drawn planter. Thus, direct seeding of basil was successful only with a hand-pushed planter. While direct seeding is a potentially viable alternative to transplanting for basil stand establishment, there is a need to identify a tractor-drawn seeder that can plant basil at the required shallow depth. In the interim, large-scale producers of basil should continue to use transplants to obtain reliable stand establishment.
\end{abstract}

Basil is one of several herbs being studied for production as an extraction processing crop in Oklahoma. Mechanical harvest and high yields will be necessary to produce the volume of fresh product needed to profitably run an extraction facility.

Basil is grown primarily from transplants (Nurzyńska-Wierdak, 2002), but the crop can be established by direct seeding (Davis, 1997; Simon, 1995). Producers are interested in direct seeding for basil stand establishment as a possible method to obtain a high volume of product at a lower production cost than might result from the use of transplants. However, direct seeding of basil is considered to be more prone to failure than transplanting

\footnotetext{
Received for publication 5 May 2015. Accepted for publication 1 June 2015.

This research was supported in part by the USDA National Institute of Food and Agriculture, project H-2026.

The information given in this publication is for educational purposes only. Mention of a trademark, proprietary product, or vendor does not constitute a guarantee or warranty of the product, nor does it imply approval or disapproval to the exclusion of other products or vendors that may also be suitable. ${ }^{1}$ Professor.

${ }^{2}$ Senior Research Specialist.

${ }^{3}$ To whom reprint requests should be addressed; e-mail brian.kahn@okstate.edu.
}

source of applied nitrogen $(\mathrm{N})$. When urea was applied, incorporation was facilitated by tillage, timely rainfall, and irrigation. Adequate supplies of other macronutrients were available from fertilization of previous trials. No fungicides or insecticides were applied. Weeds were controlled manually and with machine cultivation. Plant water requirements during germination and after crop establishment were met with rainfall supplemented by overhead sprinkler irrigation. Plots were harvested with a compact forage/ greens harvester (Kincaid Equipment, Haven, KS). The machine cut plants with a sickle bar (height of cut is detailed for individual experiments) and conveyed the cut material into plastic totes. Fresh weights were recorded immediately after harvest.

Expt. 1. This study was designed to compare raw and pelleted seed at three seeding depths. The desired seeding rate was one seed per $2.5 \mathrm{~cm}$ of row length. The hand-pushed planter (Planet Jr., Cole Planter Co., Albany, GA) planted about two raw basil seeds per $2.5 \mathrm{~cm}$ of row length at the lowest setting (plate hole $1,2.4 \mathrm{~mm}$ in diameter). This setting was used for raw seed as it was the lowest rate obtainable. A setting of plate hole 13 (Table 1) provided an approximation of one pelleted basil seed per $2.5 \mathrm{~cm}$ of row length. Progressively deeper planting was obtained by placing the standard Planet Jr. shoe in either the first, third, or fifth notch from the shoe. In the first notch, the shoe sometimes did not touch the soil and so made no furrow. Although this most shallow setting often simply dropped seeds in the wheel track, the actions of the covering "wing" shoes and press wheel of the planter were sufficient to cover all but a few of the seeds. Thus the first notch produced an average seeding depth of $\approx 5 \mathrm{~mm}$. The third and fifth notches produced seeding depths of $\approx 10$ and $20 \mathrm{~mm}$, respectively.

Seeding took place on 21 May 2008. Plots were $6.1 \mathrm{~m}$ long and rows were $0.9 \mathrm{~m}$ apart. The experimental design was a randomized complete block with four replications. Initial stands were obtained by counting all plants in each $6.1 \mathrm{~m}$ plot on 11 June. Plants were topdressed with $56 \mathrm{~kg} \cdot \mathrm{ha}^{-1}$ of $\mathrm{N}$ on 30 June. A destructive, once-over machine harvest was done on 13 Aug. with an average height of cut of $25 \mathrm{~cm}$. Final stand counts were obtained immediately after harvest.

Expt. 2. This study used the same seed type and seeding depth treatments as Expt. 1. A preplant-incorporated application of $28 \mathrm{~kg} \cdot \mathrm{ha}^{-1}$ of $\mathrm{N}$ was made on 19 May 2009 , after which seeding took place. Plots were $6.1 \mathrm{~m}$ long and rows were $0.9 \mathrm{~m}$ apart. The experimental design was a randomized complete block with four replications. Initial stands were obtained on 8 June. Plants were top-dressed with $28 \mathrm{~kg} \cdot \mathrm{ha}^{-1}$ of $\mathrm{N}$ on $9 \mathrm{July}$. A destructive, once-over machine harvest was done on 10 Aug. with an average height of cut of $25 \mathrm{~cm}$. Final stand counts were obtained immediately after harvest.

Expt. 3. This study was located adjacent to Expt. 2 and received similar soil preparation, plot spacing, and overall culture. Seeding 
took place on 19 May 2009. A $2 \times 2$ factorial treatment design was used to compare two seeding rates and two seeding depths using raw seed and the hand-pushed planter. The "full" seeding rate was obtained with plate hole 1. A reduced rate was obtained by partially closing plate hole 1 with duct tape, so that the opening resembled a letter "D." The distance from the edge of the hole to the edge of the tape at the widest horizontal opening was $1.3 \mathrm{~mm}$. Shallow $(\approx 5 \mathrm{~mm})$ and medium $(\approx 10 \mathrm{~mm})$ depths of planting were obtained by placing the standard Planet Jr. shoe in either the first or the third notch from the shoe. The experimental design was a randomized complete block with six replications. Stand and yield data were taken as in Expt. 2.

Expt. 4. This study was located adjacent to Expt. 3 and received soil preparation, plot spacing, and overall culture similar to Expts. 2 and 3. Seeding took place on 19 May 2009. A $5 \times 2$ factorial treatment design was used to compare five seeding rates and two seeding depths using the hand-pushed planter. Seeding rates were partially confounded with seed type. There was a raw seed treatment sown using plate hole 1 , and pelleted seed sown using either plate hole $13,16,19$, or 22 (Table 1). Shallow $(\approx 5 \mathrm{~mm})$ and medium $(\approx 10 \mathrm{~mm})$ depths of planting were obtained by placing the standard Planet Jr. shoe in either the first or the third notch from the shoe. The experimental design was a randomized complete block with four replications.

Table 1. Specifications for hand-pushed planter seed plate holes used in stand establishment experiments involving pelleted basil seeds, 2008-2011.

\begin{tabular}{lcc}
\hline $\begin{array}{l}\text { Seed plate } \\
\text { hole no. }\end{array}$ & $\begin{array}{c}\text { Hole } \\
\text { diam }(\mathrm{mm})\end{array}$ & $\begin{array}{c}\text { Seeding } \\
\text { rate }^{\mathrm{z}}(\mathrm{no} . / \mathrm{m})\end{array}$ \\
\hline 13 & 5.5 & 33 \\
16 & 6.3 & 52 \\
19 & 7.2 & 123 \\
21 & 7.8 & 188 \\
22 & 8.1 & 205 \\
\hline
\end{tabular}

${ }^{\mathrm{z}}$ Estimate of seeding rate of pelleted 'Genovese' basil seeds based on the mean of three test runs per seed plate hole with the hand-pushed planter (Planet Jr., Cole Planter Co., Albany, GA) under laboratory conditions.

Table 2. Interactive effects of seed type and seeding depth on stand establishment and yield of field-grown 'Genovese' basil in two experiments at Bixby, OK. ${ }^{\mathrm{z}}$

\begin{tabular}{|c|c|c|c|c|c|c|}
\hline \multirow[b]{3}{*}{ Study } & \multirow[b]{3}{*}{ Seed type ${ }^{y}$} & \multicolumn{5}{|c|}{ Seeding depth } \\
\hline & & $5 \mathrm{~mm}$ & $10 \mathrm{~mm}$ & $20 \mathrm{~mm}$ & Linear & Quadratic \\
\hline & & \multicolumn{5}{|c|}{ Initial stand (plants/m) } \\
\hline & Raw & 14 & 14 & 8 & $* *$ & NS \\
\hline Expt. 1 & Pelleted & 4 & 4 & 3 & NS & NS \\
\hline \multicolumn{7}{|l|}{$\mathrm{LSD}_{0.05}$ for seed type $=3$} \\
\hline & Raw & 28 & 26 & 14 & $* *$ & NS \\
\hline Expt. 2 & Pelleted & 7 & 5 & 2 & NS & NS \\
\hline \multicolumn{7}{|l|}{$\mathrm{LSD}_{0.05}$ for seed type $=6$} \\
\hline & \multicolumn{6}{|c|}{ Fresh wt $\left(\mathrm{Mg} \cdot \mathrm{ha}^{-1}\right)$} \\
\hline & Raw & 23.8 & 24.8 & 21.4 & NS & NS \\
\hline Expt. 2 & Pelleted & 15.5 & 12.8 & 6.6 & $* *$ & NS \\
\hline
\end{tabular}

${ }^{\mathrm{z}}$ Main effects of seed type and seeding depth in these two experiments are presented in Table 3.

${ }^{y}$ Seeding rate for raw seed $\approx 80$ seeds $/ \mathrm{m}$. Seeding rate for pelleted seed $\approx 33$ seeds $/ \mathrm{m}$.

NS, **Not significant or significant at $P \leq 0.01$, respectively. done for the previous studies, including a preplant-incorporated application of $28 \mathrm{~kg} \cdot \mathrm{ha}^{-1}$ of N. Seeding and transplanting took place on 10 May 2011. Rows were $0.9 \mathrm{~m}$ apart and plots were $6.1 \mathrm{~m}$ long. Two sets of plots were sown with pelleted seeds using the tractordrawn cone planter as in Expt. 5. Two more sets of plots were sown with pelleted seeds using the hand-pushed planter using plate hole 21 (Table 1) and the standard Planet Jr. shoe set in the first notch from the shoe. The fifth set of plots was established with plug-type basil transplants set by hand at one plant per $30.5 \mathrm{~cm}$ (20 plants per row). Each plot included four rows, as in Expt. 5. The experimental design was a randomized complete block with four replications.

Thinning to 20 seedlings in a $6.1 \mathrm{~m}$ row was done for the hand-pushed planter/thinned plots on 16 June. After thinning, initial stands were obtained by counting all plants in each $6.1 \mathrm{~m}$ plot. The intent was to also create a tractor-drawn planter/thinned treatment (to be designated M2), but stands in plots sown with the tractor-drawn planter were too sparse for thinning. However, two sets of plots (treatments designated M1 and M2) that had been sown with the tractor-drawn planter were maintained to preserve the experimental design and to provide as much data as possible.

During the experimental years, other research by some of the authors had confirmed that multiple mechanical harvests could be obtained from basil, as suggested by Simon (1995). To facilitate this, the average height of cut was adjusted to $28 \mathrm{~cm}$. Plants established by transplanting received an initial harvest on 13 July. Plants established by direct-seeding had not attained sufficient size for harvest by this date. However, on 26 July plants in all experimental plots were harvested and then top-dressed with $28 \mathrm{~kg} \cdot \mathrm{ha}^{-1}$ of $\mathrm{N}$. The study then was placed on a schedule of one harvest of plants in all plots approximately every 3 weeks. Thus, the pattern of harvest and top-dressing was repeated on 16 Aug., 7 Sept., 27 Sept., and 19 Oct.

Statistical analysis. Data were subjected to analysis of variance procedures. Main effects of seed type and seeding depth, and their interaction, were tested in Expts. 1 and 2. Main effects of seeding rate and seeding depth, and their interaction, were tested in Expts. 3 and 4 . When interactions were significant, interaction means were calculated and separated using trend analysis and the least significant difference (LSD), $P=0.05$. No data were taken in Expt. 5. Fresh weight yields were evaluated by harvest date and cumulatively in Expt. 6, with mean separation among planting methods by Duncan's multiple range test, $P=0.05$.

\section{Results}

Expt. 1. A seed type $\times$ seeding depth interaction was evident for initial stand (Table 2). Stands were higher with raw seed than with pelleted seed. Stands did not differ between $5-\mathrm{mm}$ and $10-\mathrm{mm}$ depths with either seed type. Stands decreased linearly with 
seeding depth for raw seed, but not for pelleted seed (Table 2). These patterns persisted with final stands, but the interaction no longer was evident, and the overall response to increased seeding depth was quadratic (Table 3). Yields were higher with raw seed compared with pelleted seed, and yields showed a linear decrease as seeding depth increased (Table 3).

Expt. 2. A seed type $\times$ seeding depth interaction was evident for initial stand (Table 2). The responses generally were similar to those observed in Expt. 1. Raw seed produced higher final stands than pelleted seed, but unlike Expt. 1, a quadratic response was not evident as seeding depth increased (Table 3$)$. A seed type $\times$ seeding depth interaction was evident for yield (Table 2). Yields were similar among plants established by raw seed sown $5 \mathrm{~mm}$ deep and pelleted seed sown $5 \mathrm{~mm}$ deep (Table 2). Seeding depth did not affect yields with raw seed, but yields showed a linear decrease as seeding depth increased for plants established by pelleted seed (Table 2).

Expt. 3. The full seeding rate resulted in higher initial stands, final stands, and yields than the reduced seeding rate (Table 4). Seeding depth did not affect initial and final stands, but the 5-mm seeding depth resulted in higher yields than the $10-\mathrm{mm}$ seeding depth (Table 4). Seeding rate $\times$ seeding depth interactions were not evident.

Expt. 4. Initial and final stands decreased for pelleted seed as seeding rate decreased through use of plate holes 22, 19, and 16 (Table 5). Stands further decreased numerically, but not statistically, with the lowest rate of pelleted seed (obtained using plate hole 13). Sowing pelleted seed using plate hole 22 gave higher initial stands than sowing raw seed, but this difference no longer was evident for final stands (Table 5). The highest yields resulted from use of raw seed. Planting pelleted seed using plate hole 22 resulted in higher final stands, but similar yields, compared with planting pelleted seed using plate hole 19 (Table 5). The lowest yields resulted from planting the lowest rate of pelleted seed (obtained using plate hole 13). The 5-mm seeding depth resulted in higher initial stands, final stands, and yields than the $10-\mathrm{mm}$ seeding depth (Table 5). Seeding rate $\times$ seeding depth interactions were not evident.

Expt. 5. Stand establishment failed in plots seeded with the tractor-drawn planter, so no data were taken.

Expt. 6. Transplanted plots were established to give initial stands of 20 plants in a $6.1-\mathrm{m}$ plot. The hand-pushed planter gave initial stands averaging $\approx 12$ plants/m (Table 6). However, the tractor-drawn planter gave initial stands that averaged approximately three plants $/ \mathrm{m}$, which was the desired final stand (Table 6). Therefore, the seededthen-thinned treatment could be tested only in plots established with the hand-pushed planter. Plants established by transplanting yielded more than plants established by any direct-seeding treatment on the first date when all plots were harvested (26 July)

Table 3. Main effects of seed type and seeding depth on stand establishment and yield of field-grown 'Genovese' basil in two experiments at Bixby, OK.

\begin{tabular}{|c|c|c|c|}
\hline \multirow[b]{2}{*}{ Variable } & \multicolumn{2}{|c|}{ Final stand (plants $/ \mathrm{m}$ ) } & \multirow{2}{*}{$\frac{\text { Fresh wt }\left(\mathrm{Mg} \cdot \mathrm{ha}^{-1}\right)}{\text { Expt. } 1}$} \\
\hline & Expt. 1 & Expt. 2 & \\
\hline \multicolumn{4}{|l|}{ Seed type ${ }^{z}$} \\
\hline Raw & 9 & 16 & 24.2 \\
\hline Pelleted & 3 & 4 & 14.8 \\
\hline Main effect & $* *$ & $* *$ & $*$ \\
\hline \multicolumn{4}{|l|}{ Seeding depth } \\
\hline $5 \mathrm{~mm}$ & 7 & 13 & 22.6 \\
\hline $10 \mathrm{~mm}$ & 7 & 11 & 19.6 \\
\hline $20 \mathrm{~mm}$ & 4 & 6 & 16.5 \\
\hline Depth linear & ** & $* *$ & ** \\
\hline Depth quadratic & $*$ & NS & NS \\
\hline Seed type $\times$ depth & NS & NS & NS \\
\hline
\end{tabular}

${ }^{{ }^{z}}$ Seeding rate for raw seed $\approx 80$ seeds $/ \mathrm{m}$. Seeding rate for pelleted seed $\approx 33$ seeds $/ \mathrm{m}$.

Ns, *,**Not significant or significant at $P \leq 0.05$ or 0.01 , respectively.

Table 4. Effects of seeding rate with raw seed and seeding depth on stand establishment and yield of fieldgrown 'Genovese' basil in Expt. 3 at Bixby, OK.

\begin{tabular}{lrrr}
\hline & \multicolumn{2}{c}{ Stand (plants/m) } & \\
\cline { 2 - 3 } Variable & Initial & Final & Fresh wt $\left({\left.\mathrm{Mg} \cdot \mathrm{ha}^{-1}\right)}^{\text {Seeding rate }}{ }^{\mathrm{z}}\right.$ \\
$\quad$ Full & 23 & 15 & 25.4 \\
$\quad$ Reduced & 9 & 7 & 21.0 \\
$\quad$ Main effect & $* *$ & $* *$ & $* *$ \\
Seeding depth & & & \\
$5 \mathrm{~mm}$ & 16 & 11 & 24.2 \\
$10 \mathrm{~mm}$ & 15 & 11 & 22.2 \\
$\quad$ Main effect & NS & NS & $*$ \\
Rate $\times$ depth & NS & NS & NS \\
\hline
\end{tabular}

${ }^{\mathrm{z}}$ Full seeding rate from unobstructed seed plate hole $1 \approx 80$ seeds $/ \mathrm{m}$. Reduced seeding rate from obstructed seed plate hole $1 \approx 30$ seeds $/ \mathrm{m}$.

NS, ${ }^{*}, * *$ Not significant or significant at $P \leq 0.05$ or 0.01 , respectively.

Table 5. Effects of seeding rate (one rate for raw seed compared with four rates for pelleted seed obtained using different seed plate holes) and seeding depth on stand establishment and yield of field-grown 'Genovese' basil in Expt. 4 at Bixby, OK.

\begin{tabular}{|c|c|c|c|}
\hline \multirow[b]{2}{*}{ Variable } & \multicolumn{2}{|c|}{ Stand (plants $/ \mathrm{m}$ ) } & \multirow[b]{2}{*}{ Fresh wt $\left(\mathrm{Mg} \cdot \mathrm{ha}^{-1}\right)$} \\
\hline & Initial & Final & \\
\hline \multicolumn{4}{|l|}{ Seeding rate ${ }^{\mathrm{z}}$} \\
\hline Raw seed & $18 b^{y}$ & $15 \mathrm{a}$ & $24.6 \mathrm{a}$ \\
\hline Plate hole 22 & $25 \mathrm{a}$ & $16 \mathrm{a}$ & $21.8 \mathrm{~b}$ \\
\hline Plate hole 19 & $13 \mathrm{c}$ & $10 \mathrm{~b}$ & $20.2 \mathrm{~b}$ \\
\hline Plate hole 16 & $7 \mathrm{~d}$ & $5 \mathrm{c}$ & $15.8 \mathrm{c}$ \\
\hline Plate hole 13 & $4 \mathrm{~d}$ & $3 \mathrm{c}$ & $12.6 \mathrm{~d}$ \\
\hline \multicolumn{4}{|l|}{ Seeding depth } \\
\hline $5 \mathrm{~mm}$ & 15 & 11 & 20.5 \\
\hline $10 \mathrm{~mm}$ & 12 & 9 & 17.5 \\
\hline Main effect & $*$ & * & $* *$ \\
\hline Rate $\times$ depth & NS & NS & NS \\
\hline
\end{tabular}

${ }^{\text {z} S e e d i n g ~ r a t e ~ f o r ~ r a w ~ s e e d ~} \approx 80$ seeds $/ \mathrm{m}$. Seeding rates with pelleted seed for plate holes $22,19,16$, and $13 \approx 205,123,52$, and 33 seeds $/ \mathrm{m}$, respectively.

${ }^{y}$ For seeding rates, within columns, means followed by the same letter do not differ according to Duncan's new multiple range test, $P=0.05$.

Ns, *, **Not significant or significant at $P \leq 0.05$ or 0.01 , respectively.

(Table 6). Yields did not differ between plants established by transplanting and plants established with the hand-pushed planter on subsequent harvest dates, with the exception of 7 Sept. Yields from plants established by transplanting and from plants established with the hand-pushed planter always were greater than or equal to yields from plants established with the tractor-drawn planter (Table 6). Cumulative yields did not differ for plants established by transplanting vs. plants established with the hand-pushed planter, whether or not the direct-seeded plots had been thinned. Cumulative yields were lowest for plants established with the tractor-drawn planter (Table 6).

\section{Discussion}

The use of pelleted seed was considered important for successful functioning of a large-scale tractor-drawn planter, and for precision planting, since raw basil seed is small and irregular in shape. Lower yields often were obtained from plants established with pelleted seed than from plants established 
Table 6. Effects of planting methods on stand establishment and yield of field-grown 'Genovese' basil in Expt. 6 at Bixby, OK.

\begin{tabular}{|c|c|c|c|c|c|c|c|c|}
\hline \multirow[b]{2}{*}{ Planting method ${ }^{\mathrm{z}}$} & \multirow[b]{2}{*}{ Initial stand $\mathrm{d}^{\mathrm{y}}$ (plants $\left./ \mathrm{m}\right)$} & \multicolumn{7}{|c|}{ Fresh wt $\left(\mathrm{Mg} \cdot \mathrm{ha}^{-1}\right)$ at indicated harvest date } \\
\hline & & 13 July & 26 July & 16 Aug. & 7 Sept. & 27 Sept. & 19 Oct. & Cumulative \\
\hline TPL & $3 b^{x}$ & 3.1 & $3.2 \mathrm{a}$ & $10.0 \mathrm{a}$ & $2.1 \mathrm{~b}$ & $6.6 \mathrm{ab}$ & $6.3 \mathrm{ab}$ & $31.4 \mathrm{a}$ \\
\hline HNT & $12 \mathrm{a}$ & - & $2.1 \mathrm{~b}$ & $9.4 \mathrm{a}$ & $3.5 \mathrm{a}$ & $7.4 \mathrm{a}$ & $7.6 \mathrm{a}$ & $29.9 \mathrm{a}$ \\
\hline HT & $3 \mathrm{~b}$ & - & $1.6 \mathrm{bc}$ & $9.8 \mathrm{a}$ & $3.4 \mathrm{a}$ & $5.9 \mathrm{~b}$ & $6.3 \mathrm{ab}$ & $27.0 \mathrm{a}$ \\
\hline M1 & $3 \mathrm{~b}$ & - & $0.6 \mathrm{~d}$ & $5.8 \mathrm{~b}$ & $2.3 \mathrm{~b}$ & $2.6 \mathrm{c}$ & $3.4 \mathrm{c}$ & $14.6 \mathrm{~b}$ \\
\hline M2 & $3 \mathrm{~b}$ & - & $0.9 \mathrm{~cd}$ & $5.6 \mathrm{~b}$ & $2.4 \mathrm{ab}$ & $2.7 \mathrm{c}$ & $4.4 \mathrm{bc}$ & $16.0 \mathrm{~b}$ \\
\hline
\end{tabular}

zPlanting by all methods was done on 10 May. The intent was to thin M2, but stands were too sparse; thus M1 and M2 were not thinned and were treated identically.

${ }^{y}$ Stand on 16 June after thinning HT plots. Desired stand was 20 plants in a $6.1-\mathrm{m}$ plot, or approximately three plants/m.

${ }^{x}$ Within columns, means followed by the same letter do not differ according to Duncan's new multiple range test, $P=0.05$.

$\mathrm{TPL}=$ transplanted; HNT $=$ hand-pushed planter and not thinned; HT = hand-pushed planter and later thinned to match transplanted stand; M1 and M2 = planted by tractor-drawn cone planter.

with raw seed in Expts. 1 and 2 (Tables 2 and 3 ). This result was due primarily to the lower seeding rate with pelleted seed that produced lower stands than those obtained by planting with raw seed. Final stands in plots sown with pelleted seed using plate hole 22 in Expt. 4 were similar to those in plots sown with raw seed, but plants established with raw seed yielded more than plants established with pelleted seed (Table 5). However, yields from plants established by direct seeding with pelleted seed were similar to those from plants established by transplanting in Expt. 6 (Table 6). Therefore, pelleted seed can be used for direct seeding of basil.

Expt. 3 tested the hypothesis that the seeding rate obtained by using plate hole 1 for raw seed with the hand-pushed planter might be too high. This was not found to be the case. Seeding with the narrowed plate hole 1 resulted in initial and final stands that were lower by $61 \%$ and $53 \%$, respectively, than stands obtained by seeding with the unobstructed plate hole 1 (Table 4). However, plants in the plots with the higher final stands produced the higher yields (Table 4). While these studies were not designed to test effects of plant population on basil yield, data from Expts. 1 through 4 (Tables 2-5) suggest that final stands above the common recommendation of one plant per $30.5 \mathrm{~cm}$ ( approximately three plants $/ \mathrm{m}$ ) may result in yield increases. It was not practical to obtain final stands in Expt. 6 due to plant morphological effects from the repeated machine harvests.

These experiments provide strong evidence that basil is very sensitive to seeding depth. Significant linear decreases in initial stand, final stand, and yield were seen as seeding depth increased in Expts. 1 and 2, although interactions with seed type sometimes were evident (Tables 2 and 3). Planting at a depth of $\approx 10 \mathrm{~mm}$ resulted in lower yields than planting at a depth where seeds barely were covered $(\approx 5 \mathrm{~mm})$ with soil, regardless of whether final stands differed (Expt. 4, Table 5) or did not differ (Expt. 3, Table 4). Basil seeds are not known to have a light requirement for germination (Takano, 1993), but we found that shallow planting was critical for direct seeding of basil.

Stand establishment by direct seeding using a tractor-drawn planter was attempted three times (twice in Expt. 5, once in Expt. 6). No definitive explanation was evident for the unsuccessful stand establishment by direct seeding with the tractor-drawn planter in Expt. 5 or the relatively low yields from plants established by direct seeding with the tractor-drawn planter in Expt. 6. The seeding rate should have been more than adequate. The same planter had been used to successfully direct-seed cilantro (Coriandrum sativum L.) on the same experiment station in 2006 and 2007 (Kahn and Maness, 2010). Cultural factors were favorable as indicated by the success of the other planting treatments. The most likely explanation is that the heavy tractor-drawn planter sank into the soil and placed most of the seeds at a deeper-thanoptimal depth.

Expt. 6 showed that direct-seeded basil could produce yields equal to transplanted basil, but only when direct-seeding was done using a hand-pushed planter (Table 6). Yields from plants in the two treatments established with the hand-pushed planter were similar on all harvest dates except for 27 Sept., indicating that thinning was not required. Yields from plants established with the hand-pushed planter were equal to, or better than, yields from plants established by transplanting on the last four harvest dates (Table 6). As a result, plants established with the hand-pushed planter did not differ from plants established by transplanting in cumulative yields, even though the transplanting treatment allowed one additional harvest (Table 6). Thus, direct seeding is a potentially viable alternative to transplanting for basil stand establishment. However, there is a need to identify a tractordrawn seeder that can plant basil at the required shallow depth. In the interim, large-scale producers of basil should continue to use transplants to obtain reliable stand establishment.

\section{Literature Cited}

Davis, J.M. 1997. Basil. Coop. Ext. Serv., North Carolina State Univ., Raleigh. HIL-125. 1 Oct. 2014. <http://www.ces.ncsu.edu/depts/hort/hil/ hil-125.html $>$.

Kahn, B.A. and N.O. Maness. 2010. Row arrangements, seeding rates, and gibberellic acid treatments to improve yield of machine-harvested cilantro. HortScience 45:1049-1051.

Nurzyńska-Wierdak, R. 2002. Evaluation of growth and yield of two forms of sweet basil grown from seeds and transplants. Folia Hort. 14:169-175.

Schader, C., J.G. Zaller, and U. Köpke. 2005. Cotton-basil intercropping: Effects on pests, yields and economical parameters in an organic field in Fayoum, Egypt. Biol. Agr. Hort. 23:5972.

Simon, J.E. 1995. Basil. New crop fact sheet. Purdue Univ., West Lafayette, IN. 1 Oct. 2014. <http:// www.hort.purdue.edu/newcrop/cropfactsheets/ basil.html>.

Sørensen, L. and K. Henriksen. 1992. Effects of seed rate, plastic covering, and harvest time on yield and quality of Danish grown basil (Ocimum basilicum L.). Tidsskr. Planteavl 96:499506.

Takano, T. 1993. Germination characteristics of herbs in Labiatae. Acta Hort. 331:275-286. 